\title{
Autosomal dominant pseudoxanthoma elasticum
}

\author{
F. M. POPE* \\ Institute of Dermatology, London
}

\begin{abstract}
Summary. Two families are described, each with a unique clinical variant of pseudoxanthoma elasticum (PXE) inherited in autosomal dominant fashion. Dominant type I PXE is characterized by a classical flexurally distributed rash, severe and frequent angina of effort, intermittent claudication and hypertension, and a very severe choroidoretinitis, often complicated by blindness. Dominant type II PXE, on the other hand, is a much milder form of the disease, with a macular rash (though identical histological changes), no vascular changes, and a very mild retinal degeneration, which does not progress to either blindness or choroidoretinitis. Younger members of these families often have prominent choroidal vessels. Formal analysis of the two pedigrees and all the pooled genetic data supported the autosomal dominant transmission of both these traits.
\end{abstract}

Pseudoxanthoma elasticum (PXE) is an inherited defect of elastic tissue. It is characterized by a flexurally distributed, subcutaneous lemon-yellow rash, histological examination of which shows a subcutaneous deposit of abnormally fragmented and hypertrophied elastic fibres in the middle third of the dermis (Lever, 1967). Ophthalmic complications are common with angioid streaks and a choroidoretinopathy. Intermittent claudication and gastrointestinal haemorrhage are also recognized complications (Carlborg et al, 1955; Woo and Chandler, 1958).

Most of the previous evidence has favoured autosomal recessive transmission of the disease (Cockayne, 1933; McKusick, 1973), although there has been some less convincing evidence in support of autosomal dominant transmission (Touraine, 1941). Cahill (1957) described the transmission of PXE through three generations of an Australian family and Wise (1966), in a thorough review of the literature, also found support for this hypothesis. There has been no previous report of clinical heterogeneity of the syndrome. Those who support the dominant or recessive hypothesis have tended to consider them mutually exclusive.

This paper describes two families with autosomal dominant PXE, each with clinical features suffici-

\footnotetext{
Received 5 June 1973.

* Present address: Division of Medical Genetics, Department of Medicine, Johns Hopkins University School of Medicine, Baltimore, Maryland 21205, USA.
}

ently distinctive as to suggest two separate dominant forms of the syndrome.

\section{Sources and Allocation of Patients}

In an attempted complete ascertainment of affected persons in England and Wales, 182 affected individuals were detected, 142 of whom provided detailed clinicogenetical data. There were 121 index patients and families, of which 64 were subsequently classified as autosomal dominant, and the rest recessive. The latter have been discussed elsewhere (Pope, 1972; 1974). Allocation of patients to a dominant or recessive group depended upon the pedigree patterns, so that those with multiple affected generations and with all possible combinations of parent-child transmission were placed in the dominant group, while those with affected sibs but no affected parents or children were placed in the recessive group. Singleton cases were allocated to the groups according to their clinical pattern alone.

Sources of patients included the following groups:

A. All consultant dermatologists listed by the British Association of Dermatology.

B. All consultant ophthalmologists listed by the Faculty of Ophthalmology of the Royal College of Surgeons of England.

C. All consultant physicians in Wales.

D. Medical Records Departments of (1) Teaching hospitals (England and Wales), (2) Regional Hospital Boards (England and Wales).

E. Specialized hospitals: (1) St Johns Hospital for Diseases of the Skin, London, (2) Moorfields Hospital for Eye Diseases, London. 
F. Other sources, eg, The Royal National Institute for the Blind.

\section{Procedure}

Each patient was visited and a detailed clinical history and examination was followed by the construction of an accurate pedigree. Whenever possible, all secondary patients were investigated by the same procedure. Clinical details were recorded on a standard proforma, which had the advantage of uniformity and ease of analysis at the completion of the survey.

\section{Illustrative Family Histories}

Family 1 (Fig. 1). The propositus, III.7, a man aged 47 years, had a three-year history of progressive visual loss and also angina of effort. He had a classical flexurally distributed peau d'orange rash, with scarring, pigmentation, and choroidal sclerosis. His visual acuity was diminished and there was a coincidental myopia.

A 56-year-old brother, III.4, had developed progressive visual loss two years earlier, and a longer 20year history of a progressive late onset myopia. There was also a history of angina of effort. His skin showed a classical peau d'orange PXE of which he had been unaware. The fundi showed a degenerative choroidoretinopathy with scarring, pigmentation and choroidal sclerosis. His son, IV.4, had a similar rash, but was unavailable for examination. A daughter, IV.3, was unaffected.

The older sister of the propositus, III.5, aged 55 years, had a history of progressive visual loss, intermittent claudication, and angina of effort for at least the previous 10 years. Examination showed the typical peau d'orange rash and an extensive degenerative retinopathy with severe macular damage, pigmentation, scarring, and choroidal sclerosis. She refused permission for her daughter to be contacted. Another brother, III.8, refused examination but the two remaining sibs of the propositus, III.9 and III.10, were unaffected.

The mother of the propositus, II.6, aged 75 years, had a history of recurrent angina, hypertension, and visual loss. Examination showed classical cutaneous PXE, an extensive degenerative retinopathy, and -15 dioptres of myopia. Her sister, II.9, aged 69 years had a history of two unexplained haematemeses. Examination showed classical cutaneous PXE, but no retinopathy.

A brother, II.10, aged 66 years, had no relevant history, but had typical cutaneous PXE of the neck and axillae. There was no retinopathy at the time of examination.

The grandfather of the propositus, I.3 (the father of II.6) also had a history of progressive visual deterioration and reputedly had wrinkled skin around the neck. He died aged 59 years with acute chest pain following several years of angina of effort. His nephew, II.1, aged 62 years was independently ascertained and had a similar history, with five years' progressive visual deterioration, severe angina of effort, and hypertension. The fundi showed an especially severe choroidoretinopathy and the whole posterior pole was replaced with scar tissue. There was the usual peau d'orange rash, of which he was unaware.

The mother of II.1, was I.1 the sister of I.3, who had died aged 79 years following several years of angina of effort. She also had a history of visual loss, and reputedly had yellow wrinkled skin around the neck, which was probably PXE.

Another sister of I.3 was I.5, who had three affected children. A son, II.17, aged 53 years and a daughter, II.15, both had a degenerative retinopathy. A granddaughter, III.22, aged 25 years had classical cutaneous PXE and angioid streaks.

In summary, three generations of this family showed

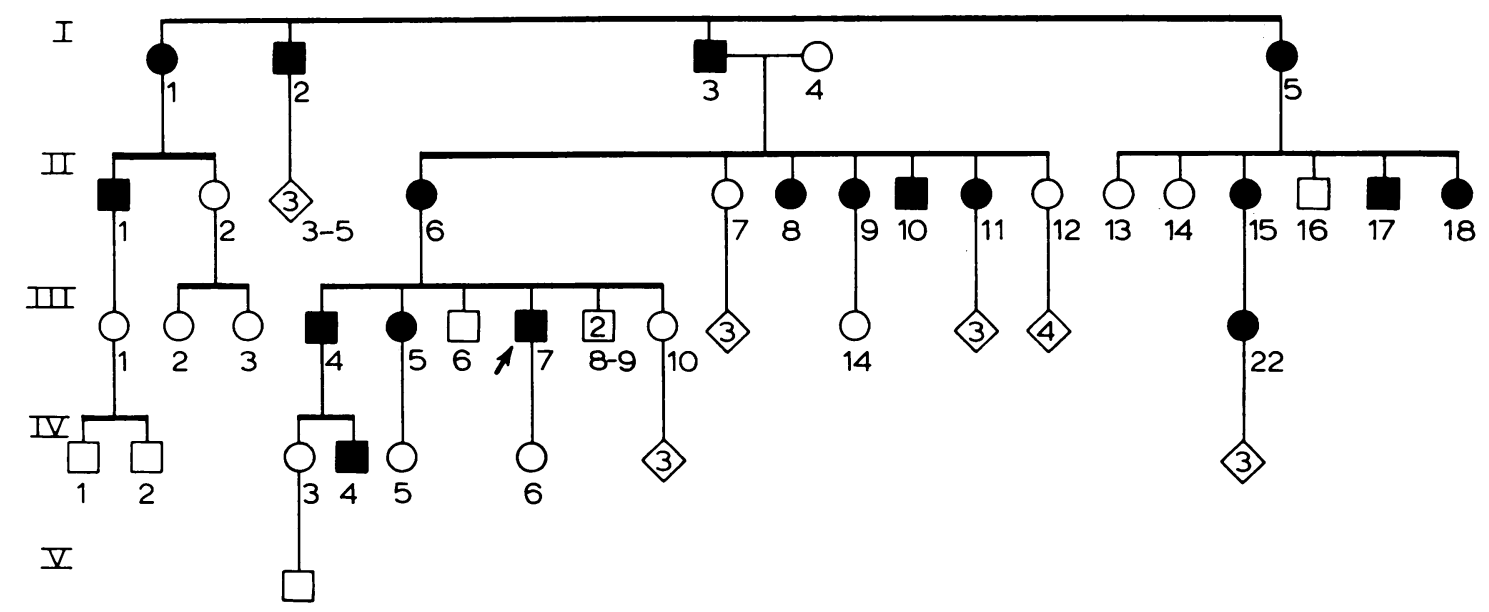


individuals affected with PXE, and a pattern of classical cutaneous peau d'orange rash, vascular complications such as angina, hypertension and intermittent claudication, and a very severe degenerative retinopathy, often complicated by blindness.

Family 2 (Fig. 2). This family showed autosomal dominant transmission of a much milder, more benign variant of PXE. The propositus, II.1, a female aged 42 years, had a history of a rash, but no visual or systemic symptoms. Examination showed a faintly pseudoxanthomatous rash around the neck and flexures. Although the visual acuity was normal, the fundi showed large myopic crescents, ill-defined circumpapillary angioid streaks, and a 'washed out' pattern without a true choroidoretinopathy. There was -4 dioptres of myopia.

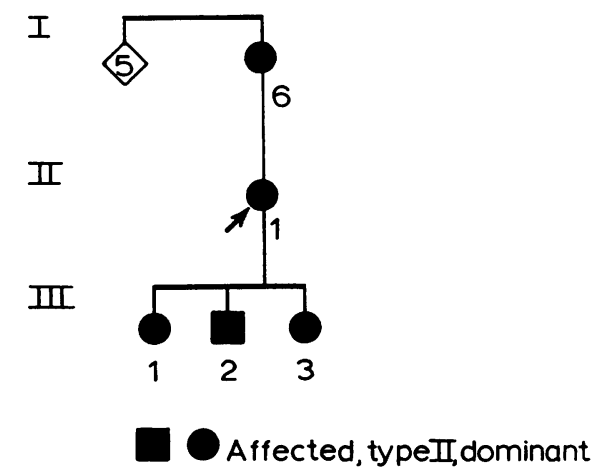

FIg. 2. Pedigree of family 2.

Her elder daughter, III.1, aged 19 years, had no symptoms. She had a faintly cream-coloured rash around the neck, which showed a slight golden yellow infiltrate when stretched. The skin over the arms, legs, face, and neck was hyperextensible. She had a high arched palate and pectus excavatum. Her joints were hypermobile by the criteria of Wynne Davies (1970). The sclerae were blue, and the fundi diffusely mottled, with very prominent choroidal vessels. There was a mild myopia of -2.5 dioptres.

The only son of the propositus, III.2, aged 18 years also had macular cutaneous PXE, increased cutaneous extensibility, and high arched palate. His fundi were mottled and he had very prominent choroidal vessels. There was a mild myopia of -3 dioptres.

The only son of the propositus, III.2, aged 18 years also had macular cutaneous PXE, increased cutaneous extensibility, and high arched palate. His fundi were mottled and he had very prominent choroidal vessels. There was a mild myopia of -3 dioptres.

The youngest daughter III.3, aged 13 years, had identical changes, except that she was not myopic.

The mother of the propositus, I.6 aged 69 years, had macular cutaneous PXE and mild degenerative 'salmon spotting' of the peripheral retina.

The histological changes of this group differed quanti- tatively from the type I family, since elastic degeneration and calcification were sparser, though hyperplasia was common.

In summary, this family had three affected generations with a mild form of PXE. This was characterized by a macular rash, no vascular complications, and a typical retinal pattern without a choroidoretinopathy.

\section{Results}

Both the illustrative families showed autosomal dominant transmission of the disease, for there were multiple generations affected with all possible combinations of parent-child transmission. The clinical patterns were quite different and suggested that there are at least two clinical variants, called PXE type I and type II, respectively, and corresponding to the two families 1 and 2 . The other families had been allocated to one or other group, depending upon the following criteria.

Type I disease was diagnosed when a classical flexurally distributed rash, vascular complications such as angina of effort, intermittent claudication and hypertension, or a severe degenerative retinopathy were observed. In type II disease the rash was much less obvious, there was no vascular disease, and the retinal changes were mild. This latter group also resembled the Ehlers-Danlos syndrome with hyperextensible skin, blue sclerae, and a high-arched palate. There were 12 families with type I, and 54 with type II PXE. Pooled clinical data from the propositi illustrate the frequencies of particular clinical signs, and pooled genetic data from each group provide statistical evidence for autosomal dominant inheritance.

Clinical Data. Table I describes the clinical characteristics of the index patients of both groups. There were important clinical differences between them. The type I group always showed the flexurally distributed, cobblestone peau d'orange skin pattern, in constrast to the type II group, where only one-quarter did so, the remainder having a typical macular, barely visible rash. In over two-thirds of the latter group, there was a generalized cutaneous hyperextensibility, similar to the Ehlers Danlos syndrome, whereas only one-twelfth of the dominant type I group were so affected.

The histology of the two types differed only quantitatively and not qualitatively. Thus type I showed the typical changes of elastic fibre fragmentation and degeneration with calcification, whereas type II show less widespread changes of this type, but with more frequent elastic fibre hyperplasia. Angina and intermittent claudication affected over half of the type I and none of the type 
TABLE I

CLINICAL DIFFERENCES OF THE TWO DOMINANT VARIANTS

\begin{tabular}{|c|c|c|}
\hline & $\begin{array}{c}\text { Dominant } \\
\text { Type I } \\
(\mathrm{n}=12)\end{array}$ & $\begin{array}{l}\text { Dominant } \\
\text { Type II } \\
\mathrm{n}=52)\end{array}$ \\
\hline $\begin{array}{l}\text { Cutaneous changes } \\
\text { Peau d'orange } \\
\text { Macular } \\
\text { Generally increased extensibility }\end{array}$ & $\begin{array}{c}12(100 \%) \\
1(\overline{8 \%})\end{array}$ & $\begin{array}{l}12(24 \%) \\
35(70 \%) \\
33(66 \%)\end{array}$ \\
\hline $\begin{array}{l}\text { Vascular disease } \\
\text { Angina } \\
\text { Claudication } \\
\text { Hypertension }\end{array}$ & $\begin{array}{l}7(56 \%) \\
7(56 \%) \\
9(75 \%)\end{array}$ & $\overline{4} \overline{(7 \cdot 8} \%)$ \\
\hline $\begin{array}{l}\text { Ophthamic } \\
\text { Severe choroiditis } \\
\text { Angioid streaks } \\
\text { Prominent (non-sclerosed) } \\
\text { choroidal vessels }\end{array}$ & $\begin{array}{c}9(75 \%) \\
4(34 \%) \\
-\end{array}$ & $\begin{array}{r}4(7 \cdot 8 \%) \\
24(47 \%) \\
9(18 \%)\end{array}$ \\
\hline $\begin{array}{l}\text { Others } \\
\text { High arched palate } \\
\text { Blue sclerae } \\
\text { Hypermobile joints }\end{array}$ & $1(\overline{8 \%})$ & $\begin{array}{l}27(54 \%) \\
21(41 \%) \\
18(35 \%)\end{array}$ \\
\hline
\end{tabular}

II group. Hypertension was observed in threequarters of the type I, but only one-twelfth of the type II group. Equally important differences occurred with the ocular complications because $75 \%$ of the type I group had a severe degenerative retinopathy, compared with only $8 \%$ of the type II group. Angioid streaks were fairly evenly distributed, affecting $34 \%$ of the type I, and $47 \%$ of the type II group. Finally, there were other similarities between the type II group and the EhlersDanlos syndrome, for $35-54 \%$ had either high arched palates, blue sclerae or hypermobile joints, in complete contrast to the type I group, only one of whom had blue sclerae, and none hypermobile joints.

Genetic Data. Both pedigrees were autosomal dominant, since there were multiple affected generations, and all possible combinations of parent to child transmission. All subsequent pedigrees, which were allocated on genetic and clinical grounds to these same groups, also satisfied these criteria and will be the subject of a separate paper. However, further evidence is presented here to support the autosomal dominant hypothesis.

Autosomal dominant traits are usually transmitted by the marriage of affected heterozygotes with unaffected wild type homozygotes, because the homozygous state is usually lethal. Therefore, the ratio of affected to unaffected should be very close to unity after correcting for bias of ascertainment. These data for the 64 dominant pedigrees are contained in Tables II and III.

Table II shows the type I groups to have been arranged as follows. Thirty-six affected and 30 unaffected males, ratio 1.2 to $1 ; 33$ affected to 37 unaffected females, ratio 0.89 to 1 ; total figures 69 affected to 67 unaffected, ratio 1.03 to 1 . This did not significantly differ from the expected values.

TABLE II

RATIO OF AFFECTED TO UNAFFECTED INDIVIDUALS (TYPE I GROUP)

\begin{tabular}{l|c|c|c}
\hline & Affected & Unaffected & $\begin{array}{c}\text { Affected/ } \\
\text { Unaffected }\end{array}$ \\
\hline Males & 36 & 30 & $\begin{array}{c}1 \cdot 2 / 1 \\
0.89 / 1\end{array}$ \\
\hline Females & 33 & 37 & \\
\hline Ratio M/F & $1.01 / 1$ & $0.98 / 1$ & $1 \cdot 03 / 1$ \\
\hline Total & 69 & 67 & 1.03 \\
\hline
\end{tabular}

Total males $=66$, total females $=70$, ratio $M / F=0 \cdot 9 / 1$.

Table III shows the dominant type II groups arranged in the same way. Thus the corresponding figures were males, 62 affected and 42 unaffected, ratio 1.48 to 1 , and females, 55 affected to 45 unaffected, ratio 1.22 to 1 , with overall figures of 117 affected and 87 unaffected, ratio 1.34 to 1 . This significantly exceeded the expected values.

TABLE III

RATIO OF AFFECTED TO UNAFFECTED INDIVIDUALS (TYPE II GROUP)

\begin{tabular}{l|c|c|c}
\hline & Affected & Unaffected & $\begin{array}{c}\text { Affected/ } \\
\text { Unaffected }\end{array}$ \\
\hline Male & 62 & 42 & $1 \cdot 48 / 1$ \\
Female & 55 & 45 & $1 \cdot 22 / 1$ \\
\hline Ratio M/F & $1 \cdot 13 / 1$ & $0.93 / 1$ & \\
\hline Total & 117 & 87 & $1 \cdot 34 / 1$ \\
\hline
\end{tabular}

Total males $=106$, total females $=100$, ratio males $/$ females $=1 \cdot 06 / 1$.

There was probably significant bias in the ascertainment of this latter group but Bernstein's (1929) correction which for reasons of random fluctuation was not needed for the type I group was applied to both sets of data (see Tables IV and V).

Type I Group (Table IV). The pedigrees were arranged by sibship size and the expected numbers per sibship of living and dead individuals with PXE compared with the observed numbers. The calculated expected number of 76.6 closely approached the observed number of 69 , with chi-squared 0.75 for 10 degrees of freedom, which was not statistically significant.

Type II Group (Table V). These data were handled in the same way as those for type I group, 
TABLE IV

BERNSTEIN'S CORRECTION FOR BIAS OF ASCERTAINMENT (TYPE I GROUP)

\begin{tabular}{c|c|c|c|c}
\hline Sibship Size & $\begin{array}{c}\text { No. of } \\
\text { Sibships }\end{array}$ & q'n & $\begin{array}{c}\text { Expected } \\
\text { Affected }\end{array}$ & $\begin{array}{c}\text { Observed } \\
\text { Affected }\end{array}$ \\
\cline { 2 - 3 } & 7 & 1.0 & 7.00 & 6 \\
2 & 7 & 1.333 & 9.33 & 10 \\
3 & 6 & 1.714 & 10.28 & 10 \\
4 & 7 & $2 \cdot 133$ & 14.92 & 13 \\
5 & 6 & 2.581 & 15.49 & 12 \\
6 & 1 & 3.048 & 3.05 & 3 \\
7 & 2 & 3.527 & 7.05 & 7 \\
8 & 1 & $4 \cdot 016$ & 4.02 & 4 \\
9 & 0 & 4.509 & 0.00 & 0 \\
10 & 0 & 5.005 & 0.00 & 0 \\
11 & 1 & 5.502 & 5.50 & 4 \\
\hline Total & & & 76.64 & 69 \\
\hline
\end{tabular}

$x^{2}=0 \cdot 75, P>0 \cdot 1$.

and the expected number of 120.33 closely approached the expected value of 119 , with chisquared 0.010 for 10 degrees of freedom.

TABLE V

BERNSTEIN'S CORRECTION FOR BIAS OF ASCERTAINMENT (TYPE II GROUP)

\begin{tabular}{|c|c|c|c|c|}
\hline Sibship Size & $\begin{array}{l}\text { No. of } \\
\text { Sibships }\end{array}$ & q'n & $\begin{array}{l}\text { Expected } \\
\text { Affected }\end{array}$ & $\begin{array}{l}\text { Observed } \\
\text { Affected }\end{array}$ \\
\hline $\begin{array}{r}1 \\
2 \\
3 \\
4 \\
5 \\
6 \\
7 \\
8 \\
9 \\
10 \\
11\end{array}$ & $\begin{array}{l}10 \\
18 \\
14 \\
12 \\
3 \\
4 \\
2 \\
1 \\
1\end{array}$ & $\begin{array}{l}1 \cdot 0 \\
1.333 \\
1.714 \\
2.133 \\
2.581 \\
3.048 \\
3.527 \\
4.016 \\
4.509 \\
5.005 \\
5.502\end{array}$ & $\begin{array}{r}10 \cdot 00 \\
23.94 \\
23.80 \\
25.60 \\
7.74 \\
12.19 \\
7.05 \\
\frac{-}{4.51} \\
\frac{5}{5.50}\end{array}$ & $\begin{array}{r}10 \\
29 \\
27 \\
26 \\
7 \\
6 \\
7 \\
2 \\
2 \\
3\end{array}$ \\
\hline Total & & & $120 \cdot 33$ & 119 \\
\hline
\end{tabular}

$x^{2}=0.010, P>0.1$.

Both sets of data supported the dominant hypothesis, departures beyond the expected values having been the result of bias of ascertainment. Furthermore the agreement implies that ascertainment had been reasonably complete.

\section{Discussion}

The evidence provided above gives clinical and genetic support to the hypothesis of two clinically distinct autosomal dominant variants of the PXE syndrome. The two families were representative of the two forms of the disease. Type I showed the classical flexurally distributed peau d'orange rash, vascular complications such as angina of effort, intermittent claudication, and a very severe degenerative retinopathy, complicated by blindness. Type II disease, on the other hand, was very much less severe, with skin lesions of the macular variety, no systemic complications, and only minimal retinal changes, although the prominent choroidal vessels which occurred among the younger members were especially important. Berlyne, Bulmer, and Platt (1961) had previously regarded them to have been heterozygote unaffected markers of homozygous recessive PXE. Duke Elder (1970), on the other hand, described their association with myopia, albinism, and fair colouring. Prominent choroidal vessels are clearly an important ophthalmic sign of the PXE syndrome. The prognosis of the two types varies, so that the clinically important type I variant has many disabling complications such as ischaemic vascular disease, hypertension and blindness, none of which apply to the type II group.

There was strong genetic support for the autosomal dominant hypothesis. This was provided in two ways.

(1) The pedigree patterns of these and other families showed multiple affected generations, with all possible modes of transmission, which included father-son, father-daughter, mother-son, and mother-daughter transmission.

(2) Formal analysis of the pooled data was of interest. There was no question of autosomal recessive transmission in any of these families. In fact, the type II group (see Table III) had more affected than unaffected individuals, so exceeding the expected one-to-one ratio. This was explained by the bias of the ascertainment, since when the data were corrected for this, then the expected one-to-one values were obtained. Other possible explanations such as undetected heterozygote marriage, or underestimation of those affected because of the subtlety of the physical signs, were unlikely alternatives.

Genetic counselling of these newly detected autosomal dominant variants of PXE is important, since the previously negligible risk of transmission of the autosomal recessive disease is increased to $50 \%$ for these dominant variants. It is particularly important when counselling for the rarer and more severe type I form, which has a much poorer prognosis than the clinically benign type II variant.

My thanks to the Dunhill Trust who supported this work during my stay at the Institute of Dermatology and to Dr R. S. Wells for constant advice and criticism. Also to Dr Victor A. McKusick, Dr Gary Chase, and Dr Alexandre Todorov of the Johns Hopkins Hospital, Baltimore, for helpful advice and criticism.

\section{REFERENCES}

Berlyne, G. M., Bulmer, M. G., and Platt, R. (1961). The genetics of pseudoxanthoma elasticum. Quarterly fournal of Medicine, 30, 201-212.

Bernstein, F. (1929). Cited in Levitan and Montagu (1971). 
Cahill, J. B. (1957). Pseudoxanthoma elasticum. Australian fournal of Dermatology, 4, 28-32.

Carlborg, U., Ejrup, B., Grönblad, E., and Lund, F. (1955). The incidence of arteriosclerosis in pseudoxanthoma elasticum. Acta Medica Scandinavica, 152, Supp. 308, 37-38.

Cockayne, E. A. (1933). Inherited Abnormalities of the Skin and its Appendages, pp. 319-321. Oxford University Press, London.

Duke-Elder, S. (1970). Pathological myopia. In System of Ophthalmology, vol. 5, ed. by S. Duke-Elder, pp. 300-357. Henry Kimpton, London.

Lever, W. F. (1967). Histopathology of the Skin, 4th edition. Lippincott, Philadelphia.

Levitan, M. and Montagu, A. (1971). Textbook of Human Genetics, pp. 424-428. Oxford University Press, London.

McKusick, V. A. (1973). Pseudoxanthoma elasticum. In Heritable
Disorders of Connective Tissue, 4th edition, ch. 10, p. 475. C. V. L. Mosby, St Louis.

Pope, F. M. (1972). Pseudoxanthoma Elasticum. MD thesis submitted to the University of Wales.

Pope, F. M. (1974). Two types of autosomal recessive PXE. Archives of Dermatology. (In press.)

Touraine, A. (1941). Une maladie peu connue: l'élastorrhexie systémmatisée. Presse Médicale, 49, pp. 361-362.

Wise, D. (1966). Hereditary diseases of connective tissue. In Handbuch Der Haut-und Geschlechtskrankheiten, ed. by. J. Jadassohn. Springer, Berlin.

Woo, J. C., Jr. and Chandler, F. W. (1958). Pseudo-xanthoma elasticum with gastric hemorrhage. Annals of Internal Medicine, 49, pp. 215-222.

Wynne-Davies, R. (1970). Acetabular dysplasia and familial joint laxity. Fournal of Bone and foint Surgery, 52B, 704. 